\title{
Myocardial infarction and coronary microvascular obstruction: an intimate, but complicated relationship
}

\author{
Gerd Heusch • Petra Kleinbongard • \\ Andreas Skyschally
}

Published online: 11 September 2013

(c) Springer-Verlag Berlin Heidelberg 2013

Keywords Coronary microembolization · Ischemic postconditioning $\cdot$ No-reflow phenomenon

Timely reperfusion is the only way to rescue ischemic myocardium from impending infarction. However, reperfusion also adds a component of injury to that incurred during ischemia and thus contributes to final infarct size [6, 20, 28]. It appears that all conditioning strategies which delay infarct size development and/or reduce infarct size act through attenuation of such reperfusion injury [7]. Apart from its contribution to cardiomyocyte necrosis, reperfusion is frequently also characterized by the development of areas of no-reflow within the previously ischemic myocardium [10]. Evidence for microvascular no-reflow by angiography or MRI despite successfully reopened epicardial coronary arteries in patients with myocardial infarction is associated with impaired recovery of ventricular function and worse survival [19].

The coexistence of infarcted cardiomyocytes and areas of coronary microvascular no-reflow in reperfused myocardium is well established [13]; however the underlying mechanisms are not really clear. Several mechanisms can initiate no-reflow in previously ischemic myocardium: (a) embolization of particulate atherosclerotic debris from the culprit lesion into the coronary microcirculation, both after mechanical or thrombolytic reopening of epicardial coronary arteries [9]; (b) platelet and platelet/leukocyte

This comment refers to the article available at doi:10.1007/s00395013-0383-8.

G. Heusch $(\bowtie) \cdot$ P. Kleinbongard · A. Skyschally

Institut für Pathophysiologie, Universitätsklinikum Essen,

Hufelandstr. 55, 45122 Essen, Germany

e-mail: gerd.heusch@uk-essen.de aggregates which are either released from the culprit lesion or form in the microcirculation [2]; (c) intense vasoconstriction in response to soluble factors (endothelin, serotonin, thromboxane) which are released from the culprit lesion [12]; (d) extravascular compression of the capillary bed by edema of the surrounding myocardium and interstitium [15]; and (e) edema and physical disintegration of the capillary vascular structures per se [13]. These pathomechanisms are not mutually exclusive, and their contribution to the no-reflow phenomenon may vary temporally and spatially as well as between different experimental models and individual patients.

The analysis of temporal and spatial relationships between infarcted myocardium and no-reflow is largely limited by methodological restraints. By definition, infarcted myocardium and no-reflow are confined to the previously ischemic area at risk. This appears trivial, but when analyzed by clinical imaging technology, the area at risk is often not determined or not clear. Slow/no-flow phenomena outside the area at risk may also occur but have a different underlying pathophysiology, e.g., reflex-mediated coronary vasoconstriction [4, 8]. Myocardial infarction develops progressively during ischemia, and a separate component of irreversible injury is added during early reperfusion; the relative contribution of infarction which develops during ischemia and during reperfusion varies and depends on the duration of ischemia [3]. Even with gold standard technology (TTC staining) in the experiment, infarcted tissue is only recognized as such after several hours of reperfusion, and no distinction between myocardium infarcting during ischemia and during reperfusion is possible. No-reflow, as evidenced by lack of endothelial staining by thioflavin in the experiment [13], develops rapidly during early reperfusion and progresses over time $[1,22,23]$. Most studies indicate that no-reflow areas are 
confined to areas of infarcted myocardium [1, 13]. However, this notion of a confinement of no-reflow to infarcted myocardium is based on experimental studies with mechanical occlusion and reperfusion of virgin coronary arteries or clinical studies using MRI several days after established reperfusion. In such experimental studies, coronary microembolization with subsequent microinfarcts into not grossly infarcted myocardium of the area at risk does not occur, and in such clinical studies using MRI coronary microembolization might occur but not be detected, as MRI identifies no-reflow areas as areas of hypoenhancement within areas of hyperenhancement, i.e., grossly infarcted myocardium [11, 23]. Microinfarction after microembolization is only detected by MRI when affecting more than $5 \%$ of myocardium [18].

The available studies indicate a close correlation between infarct size and that of no-reflow areas [21, 22]. Still, correlations cannot resolve questions of causality, and the lack of adequate techniques to make serial measurements of infarcted tissue and no-reflow with reasonable spatial resolution is largely responsible that causality between myocardial infarction and coronary microvascular no-reflow is not established. With microembolization of atherosclerotic debris, plugging of platelet/leukocyte aggregates and vasoconstriction in response to soluble mediators, the resulting coronary microvascular obstruction could be a cause to myocardial infarction. With this rationale, thrombaspiration, protection devices and coronary vasodilators are used to reduce peri-interventional reperfusion injury [9]. However, vice versa there may be primary damage to cardiomyocytes which only subsequently progresses to coronary microvascular damage, as seen in animal models with mechanical occlusion/reperfusion of virgin coronary arteries without a culprit lesion [14]. Whether cardiomyocyte damage per se is causal for subsequent coronary microvascular damage or both are consequences of the same fundamental pathomechanism, e.g., excessive reactive oxygen species formation, remains unclear. Clinically, gadolinium contrast-enhanced MRI is usually performed no earlier than a few days after reperfusion, when both infarct size and no-reflow areas are fully developed; still then the accuracy of area at risk size delineation from $\mathrm{T}_{2}$-weighted edema visualization remains questionable [27].

Ischemic postconditioning not only reduces infarct size [7], but also myocardial edema and in consequence the area at risk when delineated by $\mathrm{T}_{2}$-weighted MRI in pigs [16], and it also improves coronary microvascular perfusion in dogs [29], again emphasizing the intimate relationship between cardiomyocyte infarction and coronary microvascular obstruction and leaving potential causality unresolved.

In the present issue, Mewton et al. [17] confirm their pioneering original studies that a postconditioning maneuver of four cycles of $1 \mathrm{~min}$ re-occlusion/1 min reperfusion when performed at immediate reperfusion reduces infarct size in patients with acute ST segment elevation myocardial infarction (STEMI) $[25,26]$. In a carefully selected and characterized small cohort of patients with STEMI who presented within $12 \mathrm{~h}$ of symptom onset and had no collaterals, successful primary percutaneous coronary intervention with direct stenting and a postconditioning maneuver performed proximal to the stent not only reduced infarct size, but also the size of areas with coronary microvascular obstruction, as delineated by gadolinium contrast-enhanced MRI. Thrombus aspiration was no confounder of the observed protection, largely excluding coronary microembolization as an important pathomechanism of no-reflow in the present study. Yet, a recent study in pigs demonstrated the extension of myocardial infarction with superimposed coronary microembolization, but protection by ischemic postconditioning from infarction was even more pronounced when there was superimposed microembolization [24]. As previously shown for hypothermia [5], the present study by Mewton et al. also suggests a somewhat greater protection by ischemic postconditioning from coronary microvascular obstruction than from myocardial infarction, but still a close correlation between infarct size and size of areas with coronary microvascular obstruction.

In conclusion, ischemic postconditioning reduces infarct size, but also edema and areas of no-reflow; the pathophysiological relationships between edema, infarction and no-reflow are close, but mechanistically not clear.

\section{References}

1. Ambrosio G, Weisman HF, Mannisi JA, Becker LC (1989) Progressive impairment of regional myocardial perfusion after initial restoration of postischemic blood flow. Circulation 80:1846-1861. doi:10.1161/01.CIR.80.6.1837

2. Barrabes JA, Inserte J, Agullo L, Alonso A, Mirabet M, GarciaDorado D (2010) Microvascular thrombosis: an exciting but elusive therapeutic target in reperfused acute myocardial infarction. Cardiovasc Hematol Disord Drug Targets 10:273-283. doi: $10.2174 / 187152910793743797$

3. Garcia-Dorado D, Piper HM (2006) Postconditioning: reperfusion of "reperfusion injury" after hibernation. Cardiovasc Res 69:1-3. doi:10.1016/j.cardiores.2005.11

4. Gregorini L, Marco J, Kozàkovà M, Palombo C, Anguissola GB, Marco I, Bernies M, Cassagneau B, Distante A, Bossi IM, Fajadet J, Heusch G (1999) $\alpha$-Adrenergic blockade improves recovery of myocardial perfusion and function after coronary stenting in patients with acute myocardial infarction. Circulation 99:482-490. doi:10. 1161/01.CIR.99.4.482

5. Hale SL, Dae MW, Kloner RA (2003) Hypothermia during reperfusion limits 'no-reflow' injury in a rabbit model of acute myocardial infarction. Cardiovasc Res 59:715-722. doi:10.1016/ S0008-6363(03)00456-5

6. Heusch G (2004) Postconditioning: old wine in a new bottle? J Am Coll Cardiol 44:1111-1112. doi:org/10.1016/j.jacc2004.06.013

7. Heusch G (2013) Cardioprotection: chances and challenges of its translation to the clinic. Lancet 381:166-175. doi:10.1016/S01406736(12)60916-7 
8. Heusch G, Baumgart D, Camici P, Chilian W, Gregorini L, Hess O, Indolfi C, Rimoldi O (2000) $\alpha$-Adrenergic coronary vasoconstriction and myocardial ischemia in humans. Circulation 101:689-694. doi:10.1161/01.CIR.101.6.689

9. Heusch G, Kleinbongard P, Böse D, Levkau B, Haude M, Schulz R, Erbel R (2009) Coronary microembolization: from bedside to bench and back to bedside. Circulation 120:1822-1836. doi:10. 1161/CIRCULATIONAHA.109.888784

10. Heusch G, Kleinbongard P, Skyschally A, Levkau B, Schulz R, Erbel R (2012) The coronary circulation in cardioprotection: more than just one confounder. Cardiovasc Res 94:237-245. doi:10.1093/cvr/cvr271

11. Judd RM, Lugo-Olivieri CH, Arai M, Kondo T, Croisille P, Lima JA, Mohan V, Becker LC, Zerhouni EA (1995) Physiological basis of myocardial contrast enhancement in fast magnetic resonance images of 2-day-old reperfused canine infarcts. Circulation 92:1902-1910. doi:10.1161/01.CIR.92.7.1902

12. Kleinbongard P, Böse D, Baars T, Möhlenkamp S, Konorza T, Schöner S, Elter-Schulz M, Eggebrecht H, Degen H, Haude M, Levkau B, Schulz R, Erbel R, Heusch G (2011) Vasoconstrictor potential of coronary aspirate from patients undergoing stenting of saphenous vein aortocoronary bypass grafts and its pharmacological attenuation. Circ Res 108:344-352. doi:10.1161/ CIRCRESAHA.110.235713

13. Kloner RA, Ganote CE, Jennings RB (1974) The "no-reflow" phenomenon after temporary coronary occlusion in the dog. J Clin Invest 54:1496-1508. doi:10.1172/JCI107898

14. Kloner RA, Rude RE, Carlson N, Maroko PR, DeBoer LWV, Braunwald E (1980) Ultrastructural evidence of microvascular damage and myocardial cell injury after coronary artery occlusion: which comes first? Circulation 62:945-952. doi:10.1161/01. CIR.62.5.945

15. Manciet LH, Poole DC, McDonagh PF, Copeland JG, MathieuCostello O (1994) Microvascular compression during myocardial ischemia: mechanistic basis for no-reflow phenomenon. Am J Physiol 266:H1541-H1550

16. Mewton N, Rapacchi S, Augeul L, Ferrera R, Loufouat J, Boussel L, Micolich A, Rioufol G, Revel D, Ovize M, Croisille P (2011) Determination of the myocardial area at risk with pre- versus post-reperfusion imaging techniques in the pig model. Basic Res Cardiol 106:1247-1257. doi:10.1007/s00395-011-0214-8

17. Mewton N, Thibault H, Roubille F, Lairez O, Rioufol G, Sportouch C, Sanchez I, Bergerot C, Cung TT, Finet G, Angoulvant D, Revel D, Bonnefoy-Cudraz E, Elbaz M, Piot C, Sahraoui I, Croisille P, Ovize M. Ischemic postconditioning attenuates noreflow in STEMI patients. Basic Res Cardiol 108:383. doi:10. 1007/s00395-013-0383-8

18. Nassenstein K, Breuckmann F, Bucher C, Kaiser G, Konorza T, Schäfer L, Konietzka I, de Greiff A, Heusch G, Erbel R,
Barkhausen J (2008) How much myocardial damage is necessary to enable detection of focal late gadolinium enhancement at cardiac MR imaging? Radiology 249:829-835. doi:10.1148/ radiol.2493080457

19. Niccoli G, Burzotta F, Galiuto L, Crea F (2009) Myocardial noreflow in humans. J Am Coll Cardiol 54:281-292. doi:10.1016/j. jacc.2009.03.054

20. Ovize M, Baxter GF, Di Lisa F, Ferdinandy P, Garcia-Dorado D, Hausenloy DJ, Heusch G, Vinten-Johansen J, Yellon DM, Schulz $\mathrm{R}$ (2010) Postconditioning and protection from reperfusion injury: where do we stand? Cardiovasc Res 87:406-423. doi:10. $1093 / \mathrm{cvr} / \mathrm{cvq} 129$

21. Reffelmann T, Hale SL, Li G, Kloner RA (2002) Relationship between no reflow and infarct size as influenced by the duration of ischemia and reperfusion. Am J Physiol Heart Circ Physiol 282:H766-H772. doi:10.1152/ajpheart.00767.2001

22. Reffelmann T, Kloner RA (2002) Microvascular reperfusion injury: rapid expansion of anatomic no reflow during reperfusion in the rabbit. Am J Physiol Heart Circ Physiol 283:H1099H1107. doi:ajpheart.00270.2002

23. Rochitte CE, Lima JAC, Bluemke DA, Reeder SB, McVeigh ER, Furuta T, Becker LC, Melin JA (1998) Magnitude and time course of microvascular obstruction and tissue injury after acute myocardial infarction. Circulation 98:1006-1014. doi:10.1161/ 01.CIR.98.10.1006

24. Skyschally A, Walter B, Heusch G (2012) Coronary microembolization during early reperfusion: infarct extension, but protection by ischemic postconditioning. Eur Heart J. doi:10.1093/ eurheartj/ehs 434

25. Staat P, Rioufol G, Piot C, Cottin Y, Cung TT, L'Huillier I, Aupetit J-F, Bonnefoy E, Finet G, Andre-Fouet X, Ovize M (2005) Postconditioning the human heart. Circulation 112:2143-2148. doi:10.1161/CIRCULATIONAHA.105.558122

26. Thibault H, Piot C, Staat P, Bontemps L, Sportouch C, Rioufol G, Cung TT, Bonnefoy E, Angoulvant D, Aupetit JF, Finet G, Andre-Fouet X, Macia JC, Raczka F, Rossi R, Itti R, Kirkorian G, Derumeaux G, Ovize M (2008) Long-term benefit of postconditioning. Circulation 117:1037-1044. doi:10.1161/ CIRCULATIONAHA.107.729780

27. Wince WB, Kim RJ (2010) Molecular imaging: T2-weighted CMR of the area at risk-a risky business? Nat Rev Cardiol 7:547-549. doi:10.1038/nrcardio.2010.124

28. Yellon DM, Hausenloy DJ (2007) Myocardial reperfusion injury. N Engl J Med 357:1121-1135. doi:10.1056/NEJMra071667

29. Zhao Z-Q, Corvera JS, Halkos ME, Kerendi F, Wang N-P, Guyton RA, Vinten-Johansen J (2003) Inhibition of myocardial injury by ischemic postconditioning during reperfusion: comparison with ischemic preconditioning. Am J Physiol Heart Circ Physiol 285:H579-H588. doi:10.1152/ajpheart.01064.2002 